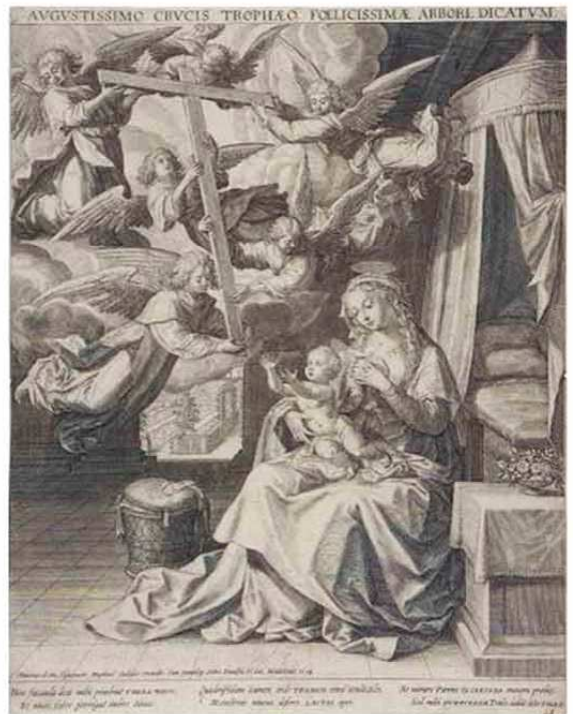

SADELER, Raphael a partir de DE VOS, Maarten. Visão da Cruz. Gravura sobre cobrc, 1614. Muscum

Plantin-Moretus/Prentenkabinet, Antuérpia.

\title{
A CIRCULAÇÃO DE GRAVURAS FLAMENGAS \\ NO VICE-REINO DO \\ PERU: TRANSFERÊNCIA \\ DE MODELOS E INVENTIVIDADE
}

\section{Flavia Galli Tatsch}

Doutora em História pela Unicamp. Professora do Departamento de História da Arte da UNIFESP. Tem como principais temas de pesquisa: história e imagens; cultura visual; transferências e circulações artísticas; arte medieval; gravuras tardo-medievais e 
TATSCH, Flavia Galli. A circulação de gravuras flamengas no Vice-Reino do Peru: transferência de modelos e inventividade. Domínios da Imagem, Londrina, v. 9, n. 17, p. 7-25, jan./jun. 2015.

ISSN 2237-9126

Recebido em 16/03/2015 e aprovado em 17/06/2015.

\section{Resumo}

Este artigo analisa a circulação de gravuras flamengas no território do ViceReino do Peru. Buscamos apresentar seu papel na produção artística local, observando a dupla perspectiva de transferência de modelos e de criação de um repertório iconográfico para os artistas nativos. Mais ainda, interessa perceber quando e como os artistas conseguiram se afastar desses modelos, criando e inserindo elementos novos.

Palavras-chave: Gravuras flamengas. Vice-Reino do Peru. Circulação e transferências artísticas.

\section{Abstract}

This paper intends to analyze the circulation of Flemish engravings on the territory of the Viceroyalty of Peru. We seek to present their role in the local artistic production, noting the dual perspective of the transfer of models and the creation of an iconographic repertoire for native artists. Moreover, it is interesting to notice when and how the artists were able to depart from these models, creating and inserting new elements.

Keywords: Flemish engravings. Viceroyalty of Peru. Circulation and artistic transfers.

\section{Introdução}

A partir do século XVI, centenas de gravuras europeias cruzaram o Atlântico nos barcos que rumavam para o Novo Mundo.' As prensas da França, Itália e Alemanha respondiam por uma parcela significativa dessa produção; no entanto, a grande maioria foi impressa nos Países Baixos, mais precisamente na cidade de Antuérpia. Além de circularem em livros, folhetos ou folhas volantes, podiam ser encontradas nas paredes de mosteiros ou de casas particulares, servindo como ornamento em igrejas isoladas das missões e que ainda não contavam com pinturas murais ou retábulos.

As gravuras desempenharam um papel significativo na produção artística, cumprindo a dupla função de transferir para os vice-reinos os estilos

\footnotetext{
1 Este artigo resulta de uma comunicação feita no Seminário Mindlin 2012 Plantin $\varepsilon$ Craesbeeck. Um mundo sobre papel: livros, gravuras e mapa na era dos descobrimentos, em junho daquele ano, organizado pela Biblioteca Brasiliana Guita e José Mindlin.
} 
TATSCH, Flavia Galli. A circulação de gravuras flamengas no Vice-Reino do Peru: transferência de modelos e inventividade. Domínios da Imagem, Londrina, v. 9, n. 17, p. 7-25, jan./jun. 2015.

ISSN 2237-9126

correntes no continente europeu e de criar um repertório iconográfico entre os artistas indígenas. O desempenho das estampas na difusão dos elementos iconográficos já era uma prática comum mesmo na Europa. Não raro, uma pintura em tela podia ser reproduzida em desenho e gravada no atelier de seu criador, fosse por ele mesmo ou por um especialista. Uma vez impressa, sua difusão era uma questão de tempo.

A produção e o comércio de gravuras eram negócios muito rentáveis. Para se ter uma ideia, em Antuérpia, por volta de 1650, existiam setenta e oito casas de carne, cento e sessenta e nove padarias e, aproximadamente, trezentos estúdios de pintura e gravura. Segundo Moxey, é possível "concluir que as estampas estavam dentro do poder de compra, não só das classes médias e alta, ricos comerciantes e profissionais, mas também de mestres e outros artesãos em geral" (MOXEY, 2004, p. 23).

Este artigo trata da apropriação e circularidade das gravuras flamengas na pintura sacra do Vice-Reino do Peru. Nossa intenção é apontar alguns exemplos de apropriação e circularidade das imagens. Claro está que esse fenômeno se deu tanto no âmbito da pintura religiosa como sacra, mas aqui interessa somente o primeiro.

\section{Circulação de gravuras e livros religiosos flamengos no Vice-Reino do Peru}

Christophe Plantin (1514-1589) foi um impressor francês que se mudou, em 1549, para Antuérpia, o mais importante centro tipográfico de então. Por privilégio real de Felipe II, sua oficina adquiriu o monopólio de impressão e comercialização de livros religiosos para todo o império espanhol. Um dos seus mais significativos projetos editoriais ficou conhecido como Libros del Nuevo Rezado, grande revisão dos textos litúrgicos promovida a partir do Concílio de Trento, cujo objetivo era unificar os conteúdos dos livros utilizados nas igrejas. Tal controle por parte da lgreja tridentina só poderia dar certo se os textos não fossem mais impressos nas pequenas oficinas locais, mas sim 
TATSCH, Flavia Galli. A circulação de gravuras flamengas no Vice-Reino do Peru: transferência de modelos e inventividade. Domínios da Imagem, Londrina, v. 9, n. 17, p. 7-25, jan./jun. 2015.

ISSN 2237-9126

levados a cabo por casas editoras bem estruturadas e com uma logística de distribuição em grande escala. Não à toa, a Officina Plantiniana se transformou na empresa editorial mais importante entre 1570 e 1625. Para se ter uma ideia, no intervalo de cinco anos (1571-1576), Plantin enviou à corte aproximadamente dezenove mil breviários, dezessete mil missais e nove mil Livros de Horas (SORIA, 1952; KELEMEN, 1967, p. 201).

Grande parte da circulação dos livros religiosos flamengos no ViceReino do Peru se deu a partir de Lima, centro administrativo, político e cultural. A Ciudad de los Reyes, como era chamada, foi dotada com uma universidade (1551), vários colégios de distintas ordens religiosas e bibliotecas. A alimentar a necessidade de saber que vinha dessas instituições estavam livreiros (já desde a metade do século XVI), tipógrafos (a primeira imprensa limenha foi fundada em 1584 pelos jesuítas para dar suporte ao processo de evangelização) e encadernadores. Outras cidades também se tornaram importantes centros irradiadores da vida cultural peruana, como Cuzco, Potosí, La Plata e Santiago do Chile. Claro está que nem todos os livros que chegavam tinham sido impressos em Flandres, muitos saíram de importantes centros editoriais espanhóis, como Alcalá de Henares, Madri, Medina del Campo, Toledo, Zaragoza, Salamanca; assim como de Paris, Roma, Veneza.

A difusão e a venda dos livros flamengos no vice-reino podiam se dar através da comercialização empreendida pelos livreiros, das encomendas às pessoas que viajavam à Europa ou da circulação promovida dentre as bibliotecas de uma mesma ordem religiosa. Neste caso, vale citar como exemplo a atuação do Colégio de San Pablo: pouco tempo depois de sua fundação em 1568, os jesuítas criaram a biblioteca do colégio que, desde então, se configurou como uma das melhores e mais importantes da região. Para se ter uma ideia, por volta de 1760, suas instalações abrigavam aproximadamente vinte e cinco mil volumes. San Pablo não só acumulava livros como também era responsável por emprestar a domicílio (SALAZAR- 
TATSCH, Flavia Galli. A circulação de gravuras flamengas no Vice-Reino do Peru: transferência de modelos e inventividade. Domínios da Imagem, Londrina, v. 9, n. 17, p. 7-25, jan./jun. 2015.

ISSN 2237-9126

SOLER, 2009, p. 221) e enviar exemplares para os "quatro pontos cardinais". No século XVII, milhares de volumes partiram nos lombos das mulas para

[...] o norte, para o colégio de Trujillo e as missões de Mainas, até o sul para os colégios de Arequipa e Pisco, e as haciendas de lca e Nazca; para o sudeste, atravessando a cordilheira dos Andes, para as bibliotecas jesuítas de Huamanga, Hancavelca, Cuzco, Juli, nas margens do Lago Titicaca, La $\mathrm{Paz}$, Oruro, Chiquisaca (que por exemplo recebeu cem volumes só em 1627), Cochabamba e Potosí, e incluindo mais além, para o colégio de Tucuman, a Universidade de Córdoba, La Plata ou Santiago do Chile [...] (SALAZAR-SOLER, 2009, p. 225).

Além do texto, o grande atrativo das publicações flamengas advinha do fato de estarem acompanhadas por ilustrações elaboradas pelos mais destacados artistas e mestres gravadores. O impacto dessas imagens foi apontado por Kelemen, que o sistematizou em quatro etapas, sendo a primeira com mestres ativos no período entre 1570 e 1630: Hendrick Golzius (1526-1583); Hans Bol (1534-1593); Maarten de Vos (1532-1603); da família Sadeler, Jan I (1550-1600), Aegiudius I (1570-1692) e Raphael I (1561-1632); Philips Galle (1537-1612) e seu genro Adriaen Collaert (ca. 1560-1618); os irmãos Wierix, Jan (c. 1549-c. 1618) Hyeronimus, (1553-1619) e Anton II (c. 1555/59-1604); e Karel de Mallery (Ca. 1566-1628). Ficamos por aqui porque a lista é imensa. A segunda etapa se deu com Rubens e membros de seu estúdio, como Lucas Vosterman, o velho (1595-1675), Paulus Pontius (16031658) e os irmãos Boswert, Laurers. A terceira, datada no final do século XVII, contou com a presença de obras Abraham van Diepenbeek (1596-1675) e Richard Collin (1626-depois de 1687). Por último, no século XVIII, Richard van Orley (1663-1732) e Cornelis Johannes d'Heur. 
TATSCH, Flavia Galli. A circulação de gravuras flamengas no Vice-Reino do Peru: transferência de modelos e inventividade. Domínios da Imagem, Londrina, v. 9, n. 17, p. 7-25, jan./jun. 2015.

ISSN 2237-9126

\section{As muitas visões da cruz}

A circular pelas Américas estavam centenas de gravuras. Sua importância nos processos de elaboração da pintura nos vice-reinos veio a reboque do renascimento da espiritualidade católica frente ao advento da Reforma protestante, levada a cabo pelo Concílio de Trento e pela Companhia de Jesus. Fazia-se necessário divulgar entre os cristãos o exemplo da vida dos evangelistas, mártires paleocristãos, apóstolos, santos, doutores da Igreja e dos fundadores das novas ordens religiosas. Nesse sentido, as imagens se tornaram um inacreditável instrumento de comunicação, bem como deveriam comover àqueles que as viam.

O problema da evangelização enfrentado pela Espanha em suas colônias de além-mar se fazia cada vez mais premente. O terceiro Concílio de Lima (1582-1583) procurou estruturar a catequização dos povos que viviam na região andina. Entre as decisões tomadas, estava a de redigir textos em espanhol, quechua e aymará, e a de procurar transmitir os principais conceitos cristãos mediante imagens. Entretanto, os artistas indígenas ou mestizos não estavam suficientemente familiarizados com os códigos iconográficos que permeavam a hagiografia cristã. Tampouco tinham a oportunidade de se deslocarem para os centros artísticos europeus a fim de reciclar seus conhecimentos.

Assim, a pintura e as gravuras flamengas vinham ao encontro de uma demanda cada vez maior de modelos para a produção local, constituindo "a principal fonte de inspiração para a temática dos pintores americanos. Hoje estamos seguros que são muito poucos os Mestres que escaparam a tão poderoso influxo da estampa" (MESA e GISBERT, 1956, p. 68). A provisão das estampas podia ser feita pelos comitentes - funcionários reais, superiores de conventos e mosteiros, particulares - ou pelo próprio artista. Em 1587, o pintor italiano residente em Lima, Mateo Pérez de Alesio, assinou nota promissória em que se comprometia a pagar quinhentos e vinte ducados ao 
TATSCH, Flavia Galli. A circulação de gravuras flamengas no Vice-Reino do Peru: transferência de modelos e inventividade. Domínios da Imagem, Londrina, v. 9, n. 17, p. 7-25, jan./jun. 2015.

ISSN 2237-9126

livreiro da principal igreja de Sevilha pela encomenda de um álbum de desenhos e um livro contendo "todas as gravuras" de Dürer e de outros mestres. O pintor mestizo equatoriano Miguel de Santiago também possuía um álbum de gravuras flamengas e holandesas. Segundo o relato de viajante contemporâneo, Santiago "nunca teria saído de sua cidade nativa, embora suas pinturas fossem amplamente admiradas e algumas foram enviadas até Roma" (KELEMEN, 1967, p. 203). Logo, não há dúvida alguma sobre essa via de transferência de modelos para a arte da América Hispânica.

No passado, grandes historiadores da arte do Vice-Reino afirmaram que "em muitos casos, estão copiados tão fielmente, que o artista não se separa nem um ápice da composição original" (MESA e GISBERT, 1956, p. 68). No entanto, o que devemos levar em conta é que a emulação dos modelos não pressupunha a negação de superação dos mesmos. Também precisamos pensar que, mesmo tendo como fonte um modelo que the era exterior, tanto o comitente, como o artista, quanto o público eram diferentes do europeu. Daí a impossibilidade de afirmar que os artistas nativos ou mestizos simplesmente imitavam. Há que se levar em conta sua criatividade e capacidade de inserir novos elementos e significados. Estamos falando da inventividade, pois a aplicação de uma gravura como modelo podia resultar em diversas obras, cada qual com um resultado distinto.

É o caso da Visão da Cruz (figura 1) gravada em 1614 por Raphael Sadeler 12, a partir do desenho de Maarten de Vos3, que teve uma ampla difusão no Vice-Reino do Peru. No primeiro plano, a Virgem, sentada portando vestes longas e de dobras bem marcadas, a cabeleira solta que cai livremente sobre seu corpo, oferece o seio ao Menino. Mas, este está interessado na cruz que the é oferecida por seis anjos, de acordo com o

\footnotetext{
2 Raphael Sadeler I pertenceu a uma das mais influentes famílias de gravadores ativas no final do século XVI e início do seguinte.

3 Maarten de Vos foi pintor e um dos mais prolíficos desenhistas para gravuras de sua geração.
} 
TATSCH, Flavia Galli. A circulação de gravuras flamengas no Vice-Reino do Peru: transferência de modelos e inventividade. Domínios da Imagem, Londrina, v. 9, n. 17, p. 7-25, jan./jun. 2015.

ISSN 2237-9126

texto latino na margem superior: Augustissimo Crucis Trophaeo, Foelicissimae Arbori, dicatum. À direita da Virgem, está o leito coberto; à esquerda, vê-se um belo jardim. Vejamos, a seguir, algumas pinturas elaboradas a partir dessa imagem.

Figura 1

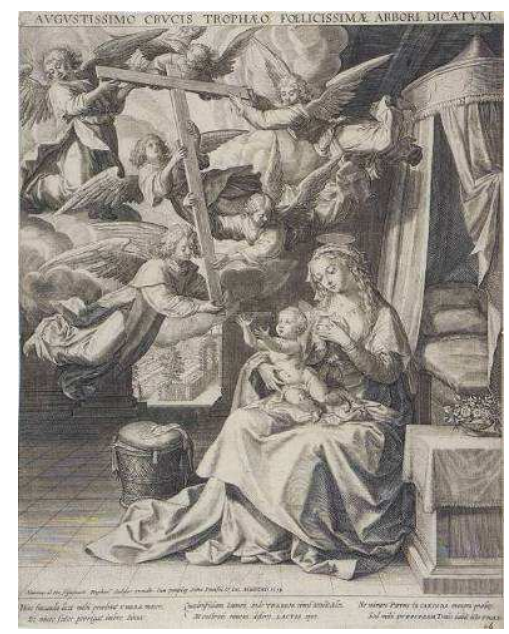

SADELER, Raphael a partir de DE VOS, Maarten. Visão da Cruz. Gravura sobre cobre, 1614. Museum Plantin-Moretus/Prentenkabinet, Antuérpia.

A figura 2, do pintor anônimo da Escola de Cuzco, encontra-se na sacristia da Igreja de Huanoquite, em Cuzco. Nela, vemos a permanência de muitos elementos da gravura, como a posição da Virgem e do Menino, o número de anjos que trazem a cruz - ainda que a obra esteja bem danificada, podemos supor que havia um sexto anjo -, a posição do jardim e do leito, o cesto à direita da mulher, seus cabelos soltos. O mesmo pode ser dito para a tela de outro pintor desconhecido (figura 3), no acervo da Coleção Barbosa-Stern, em Lima: a Virgem e o Menino, o mesmo número de anjos, sua disposição e direção dos olhares; o vaso de flor sobre a mesa à

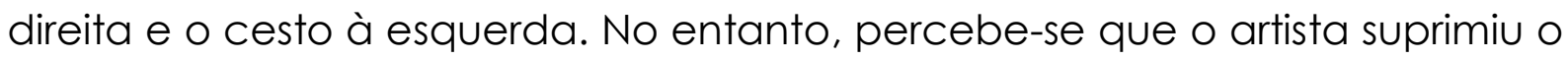
jardim, o detalhamento do leito e os cabelos da mãe de Jesus estão cobertos com um véu. Em comum, as figuras 2 e 3 não trazem a auréola da Virgem. 
TATSCH, Flavia Galli. A circulação de gravuras flamengas no Vice-Reino do Peru: transferência de modelos e inventividade. Domínios da Imagem, Londrina, v. 9, n. 17, p. 7-25, jan./jun. 2015.

ISSN 2237-9126
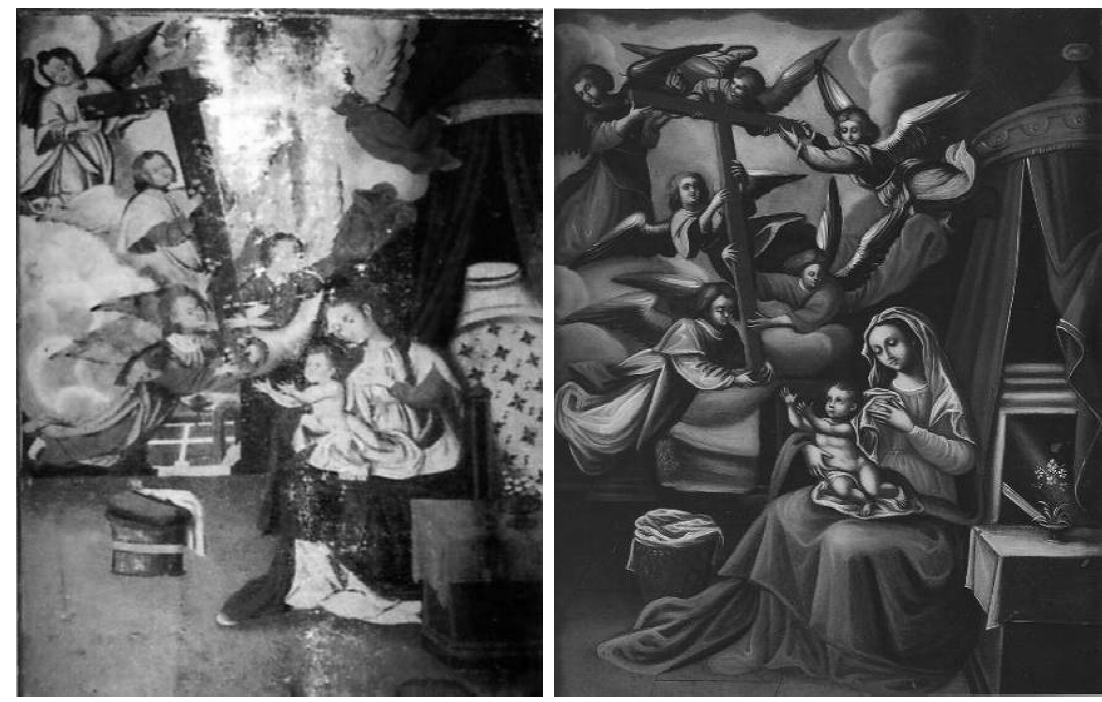

Figura 2 (esq). ANÔNIMO. Escola de Cuzco. Óleo sobre tela, sem data. Sacristia, Igreja de Huanoquite, Cuzco.

Figura 3 (dir). ANÔNIMO. Óleo sobre lâmina de cobre. Cuzco, c. 1650. Coleção Barbosa-Stern, Lima.
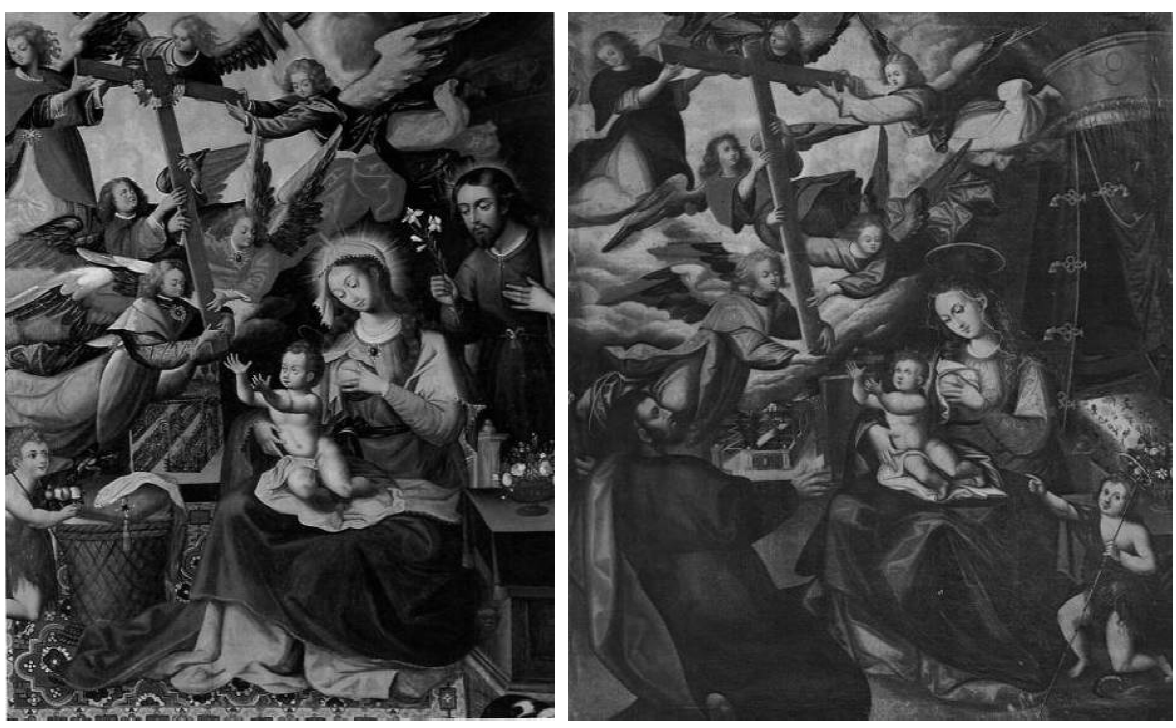

Figura 4 (esq). GAMARRA, Gregório. Óleo sobre tela, 1601-1612. Igreja da Recoleta, Cuzco.

Figura 5 (dir). TITO, Diego Quispe. Óleo sobre cobre, 1631. Convento de São Domingo, Cuzco. 
TATSCH, Flavia Galli. A circulação de gravuras flamengas no Vice-Reino do Peru: transferência de modelos e inventividade. Domínios da Imagem, Londrina, v. 9, n. 17, p. 7-25, jan./jun. 2015.

ISSN 2237-9126

Observemos a obra de Gregorio Gamarra (1570-1642), padre jesuíta que trabalhou em Cuzco, Potosí e La Paz, cuja obra marcou a pintura do vice-reino nas primeiras décadas do século XVII. Entre 1601-1612, pintou um óleo sobre tela para a Igreja da Recoleta, em Cuzco (figura 4): nas permanências, podemos destacar os seres celestiais e o jardim - aliás, muito bem detalhado - e grande parte dos pormenores da vestimenta da Virgem. Mas, percebam que Gamarra insere dois personagens que não faziam parte da gravura: à esquerda da Virgem está São José e, ajoelhado ao lado do cesto, está o jovem João Batista. Esses dois santos também aparecem na obra de Diego Quispe Tito (1611-1681), considerado o grande mestre da Escola Cusquenha que se caracterizava pela originalidade oriunda da mescla entre a tradição artística europeia e o afã dos pintores nativos em expressar sua realidade e visão de mundo.

Descendente de uma família nobre inca, Quispe estudou as gravuras europeias, das quais "emprestou motivos, detalhes", distribuindo-os de forma original (BAILEY, 2005, 297). A partir da gravura de Sadeler, Quispe Tito pintou um óleo sobre cobre para o Convento de São Domingo (figura 5). Os elementos iconográficos em comum são: a posição do menino Jesus; a cruz e os anjos; a casa e seu jardim; o céu e as nuvens; assim como a pose da Virgem e as dobras de suas vestes, quase idênticas ao original. Mas, as correspondências terminam por aí e é interessante observar como ele inseriu outros elementos. Enquanto na gravura, os cabelos de Maria caem livremente, na pintura estão cobertos com uma espécie de véu (como na figura 3); a cortina que cobre o leito ganhou quatro grandes fivelas. E, como na tela de Gamarra (figura 4), São João Batista e São José marcam presença, respectivamente, à esquerda e à frente da Virgem. Tradicionalmente, São José era representado como um homem velho, mas o pintor inca o mostrou em uma face jovem. Tal mudança na iconografia do pai de Jesus foi impulsionada, em parte, pela promoção de seu culto por Santa Teresa d'Ávila (1515-1582). Responsável pela fundação de mais de 
TATSCH, Flavia Galli. A circulação de gravuras flamengas no Vice-Reino do Peru: transferência de modelos e inventividade. Domínios da Imagem, Londrina, v. 9, n. 17, p. 7-25, jan./jun. 2015.

ISSN 2237-9126

uma dezena de conventos carmelitas em Espanha, Teresa considerava a Sagrada Família como um símbolo da Santíssima Trindade na terra. Ao inserirem São José e São João Batista, tanto Gamarra quanto Quispe Tito foram de encontro à frase latina na margem superior da gravura - que explica que o Cristo criança escolheu a cruz em lugar do seio de sua mãe e colocaram em movimento uma cena terrestre e não celestial (KELEMEN, 1967, p. 212).

\section{Jerônimo Nadal e as Imagens da História Evangélica}

A circular pelas Américas estava também uma publicação que teve ampla difusão e significativa importância tanto na arte do Vice-Reino do Peru, quanto como ferramenta de evangelização dos indígenas. Trata-se da obra do jesuíta espanhol Jerônimo Nadal (1507-1580), Evangelicae Historiae Imagines [Imagens da História Evangélica], elaborada a pedido de Ignácio de Loyola. A história dessa obra começou muito antes de sua impressão. Em 1562, São Francisco de Borja (1510-1572), terceiro general da Companhia de Jesus, desenvolvia o projeto de compilar um livro, mais precisamente, uma coleção de imagens acompanhadas de anotações, para o ensino e a educação dos noviços (ALCALÁ, 1993, p.48). Ou seja, era pensado para ser usado na formação dos jovens jesuítas a fim de criar um hábito de oração, intimamente ligado ao material visual. Como argumentou Buser, o uso da imagem visual "fazia parte de um programa estético consciente" empregado como propaganda sobre o significado dos mártires e destinado à batalha contra os protestantes (BUSER, 1976, p. 424). É provável que, em 1579, Nadal tenha terminado as notas e as meditações que acompanhariam as imagens. Também é possível que ele tenha colaborado com um artista italiano para as ilustrações ao longo dos dois anos em que viveu em Roma (BUSER, 1976, p. 425). 
TATSCH, Flavia Galli. A circulação de gravuras flamengas no Vice-Reino do Peru: transferência de modelos e inventividade. Domínios da Imagem, Londrina, v. 9, n. 17, p. 7-25, jan./jun. 2015.

ISSN 2237-9126

Os jesuítas recorreram à Plantin para publicar o livro. Kelemen nos conta uma história interessante sobre o processo de escolha dos responsáveis pelas imagens. Em cinco de novembro de 1585, a casa impressora descreveu aos jesuítas a dificuldade de se encontrar gravadores para essa tarefa. Os motivos eram diversos: ou eles se encontravam relutantes em relação ao trabalho, ou estavam comprometidos com outras publicações ou, pior ainda, fora da cidade. Vale lembrar que um dos motivos da dificuldade enfrentada se devia à revolta pela qual passavam os Países Baixos, em sua luta de independência da Espanha. Com muita relutância, há a menção da disponibilidade dos irmãos Wierix (ativos entre 1552 e 1615), Jan (c. 1549-1604), Hyeronimus (1553-1619) e Anton II (c. 1555/59-1604), cuja produção artística era reconhecida pela sofisticação técnica e delicadeza. A maioria da produção dos Wierix era religiosa e vinha ao encontro da Contrarreforma. Mas, o problema da indicação dos irmãos para a tarefa repousava em sua reputação, que não era das melhores: para seus colegas, viviam em devassidão ou na boemia e tinham um caráter repreensível. Depois de anos de negociação, a colaboração dos Wierix foi, finalmente, aceita.

Imagens da História Evangélica reuniu, em sua elaboração, os maiores expoentes gravadores de Flandres. Dos cento e cinquenta e três desenhos preparatórios, cento e vinte e seis foram elaborados pelo italiano Bernardo Pasari e o resto por Maarten de Vos. A maioria das matrizes foi impressa pelos Wierix, mas Adrian Collaert e Karel de Mallery também contribuíram para esse processo. Já em 1593, ano da primeira impressão, a obra conheceu um tremendo sucesso, sendo uma das publicações da oficina Plantin-Morteus (morto em 1589) mais divulgada em Espanha e em suas diversas colônias pelo mundo. Uma vez que o livro saltou das prensas trinta e sete anos depois da morte de Ignácio de Loyola e treze da de Nadal, há que se pensar até que ponto o produto final saiu como tinham desejado ambos os padres (BUSER, 1976, p.424). 
TATSCH, Flavia Galli. A circulação de gravuras flamengas no Vice-Reino do Peru: transferência de modelos e inventividade. Domínios da Imagem, Londrina, v. 9, n. 17, p. 7-25, jan./jun. 2015.

ISSN 2237-9126

Na edição de 1593, as ilustrações vinham em ordem cronológica da vida de Jesus; já nas posteriores, de 1594 e 1595, sob o título Adnotationes et Meditationes in Evangelia [Notas e meditações sobre os Evangelhos], as imagens vinham acompanhadas de um texto mais extenso e estavam rearranjadas de acordo com as leituras utilizadas no ano litúrgico. Em todas as pranchas, a história central estava circundada de outras cenas a ela relacionadas. Cada episódio contava com uma letra do alfabeto para sua identificação, cuja explicação era dada por uma legenda logo abaixo da imagem, contendo breves descrições e demarcando o processo narrativo que deveria ser acompanhado pelo leitor. Na sequência ao conjunto de imagens, ou seja, na segunda parte do livro, Nadal escreveu a exegese de cada um dos episódios, sugerindo uma meditação ou oração correspondente.

Tanto Imagens da História Evangélica quanto Notas e meditações sobre os Evangelhos cruzaram o Atlântico rumo ao Novo Mundo. Segundo Garcia Saiz, é possível afirmar que, em meados do século XVII havia em Ayuacucho uma "oficina de pintura que tinha como temática fundamental a reprodução de imagens procedentes da obra de Nadal, direta ou indiretamente" (apud NADAL CAÑELLAS, 2007, p.240), misturando-as com elementos novos ou combinando-as entre si. Para o primeiro caso, da emulação, podemos citar a prancha 79 de Imagens da História Evangélica, gravada por Anton Wierix (figura 6), sobre a reunião em que o conselho deliberou sobre a morte de Jesus [Concilium de nece IESV], "reproduzida" por um pintor anônimo da Escola de Huamanga (entenda-se Ayacucho). Sua função didática foi mantida e é notável a permanência dos elementos na disposição dos personagens, dos elementos arquitetônicos (como as janelas ao fundo), dos móveis, dos pequenos diabos sobre as cabeças dos participantes do conselho, e até mesmo nas letras correspondentes a cada cena e personagem registrados e sua explicação nas legendas abaixo da imagem (figura 7). 
TATSCH, Flavia Galli. A circulação de gravuras flamengas no Vice-Reino do Peru: transferência de modelos e inventividade. Domínios da Imagem, Londrina, v. 9, n. 17, p. 7-25, jan./jun. 2015.

ISSN 2237-9126

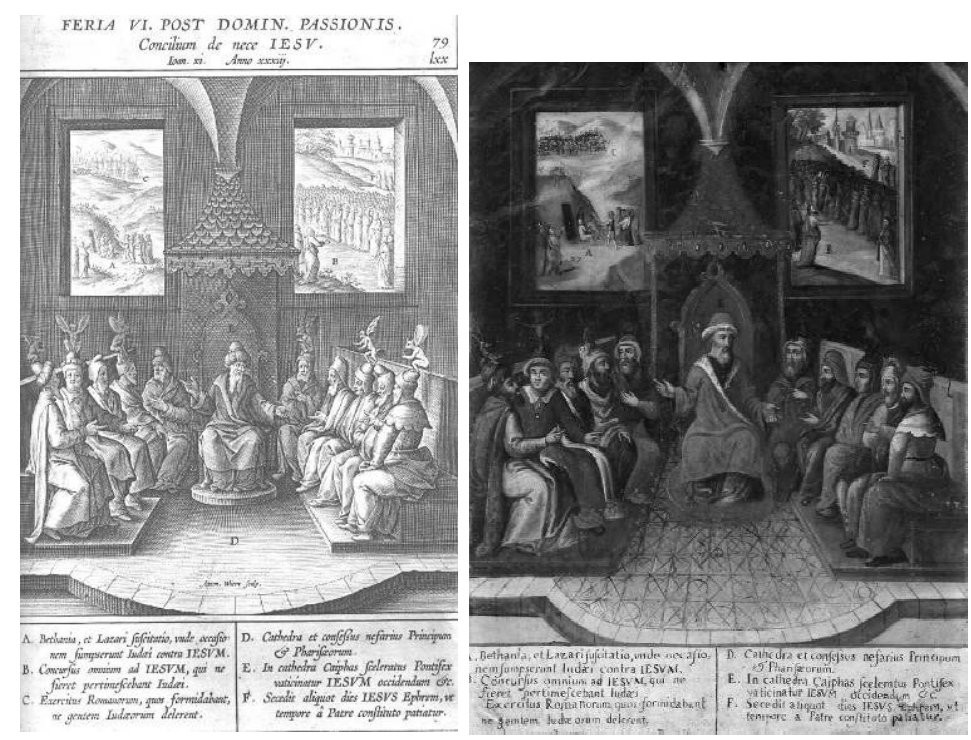

Figura 6 (esq). WIERIX, Anton. Lâmina 79. NADAL, Jerônimo. Evangelicae Historiae Imagines, 1593. Gravura.

Figura 7 (dir). ANÔNIMO. O Conselho delibera sobre a morte de Jesus. Escola de Huamanga, século XVIII. Óleo sobre cobre. Coleção Barbosa-Stern, Lima

Como mencionado acima, nem sempre os artistas do Vice-Reino do Peru seguiam à risca a composição dos Wierix. A prancha 121 da edição de 1593, Flagelação [Flagellatvr Christvs] (figura 8), foi utilizada como modelo em duas telas distintas: a do pintor Anônimo e que pertence à Coleção Barbosa-Stern (figura 9), em Lima, e a de Isidoro de Moncada (figura 10), na Igreja de Ayaviri, em Puno. Ambas as pinturas se basearam na gravura de Wierix, o que revela seu impacto para a escolha do tema bem como 0 tratamento dos elementos iconográficos abordados pelos artistas, com a representação da flagelação em primeiro plano e no centro de toda a cena, para a qual convergem todos os olhares das testemunhas. O Cristo, cuja pele é muito branca, tem cabelos compridos e barba e, por detrás de sua cabeça, uma auréola composta por raios dourados. Seu corpo, com o torso nu, recebe os açoites dos soldados romanos dispostos ao seu redor. 
TATSCH, Flavia Galli. A circulação de gravuras flamengas no Vice-Reino do Peru: transferência de modelos e inventividade. Domínios da Imagem, Londrina, v. 9, n. 17, p. 7-25, jan./jun. 2015.

ISSN 2237-9126
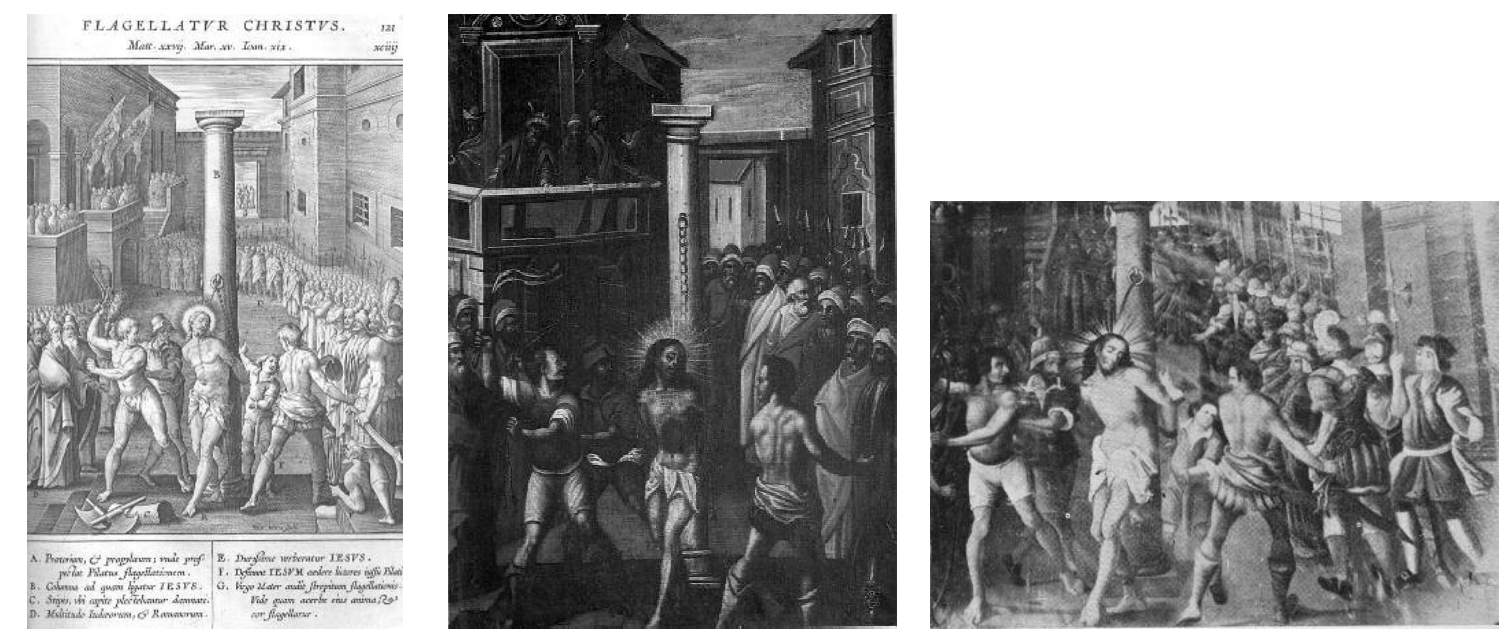

Figura 8 (esq.). WIERIX, Hieronimus. Lâmina 121. NADAL, Jerônimo.

Evangelicae Historiae Imagines, 1593. Gravura.

Figura 9 (centro). ANÔNIMO. A Flagelação. Huamanga, século XVIII. Óleo sobre tela. Coleção Barbosa-Stern, Lima.

Figura 10 (dir.). MONCADA, Isidoro de. A Flagelação. Óleo sobre tela, sem data. Igreja de Ayaviry, Puno.

Como não há, neste artigo, espaço para descrições mais detalhadas, interessa-nos apontar a liberdade dos artistas na criação e inserção de elementos que não se encontravam em Wierix e que vinham ao encontro das necessidades específicas da catequese no Novo Mundo. Em meio aos personagens, vemos rostos de mestizos e de índios cristianizados segundo as convenções artísticas da época (figura 11). O importante a ressaltar é que a inventividade se deu não só pela genialidade do pintor, como também com a intenção de converter os nativos nos novos protagonistas da história cristã da salvação. 
TATSCH, Flavia Galli. A circulação de gravuras flamengas no Vice-Reino do Peru: transferência de modelos e inventividade. Domínios da Imagem, Londrina, v. 9, n. 17, p. 7-25, jan./jun. 2015.

ISSN 2237-9126

\section{Figura 11}
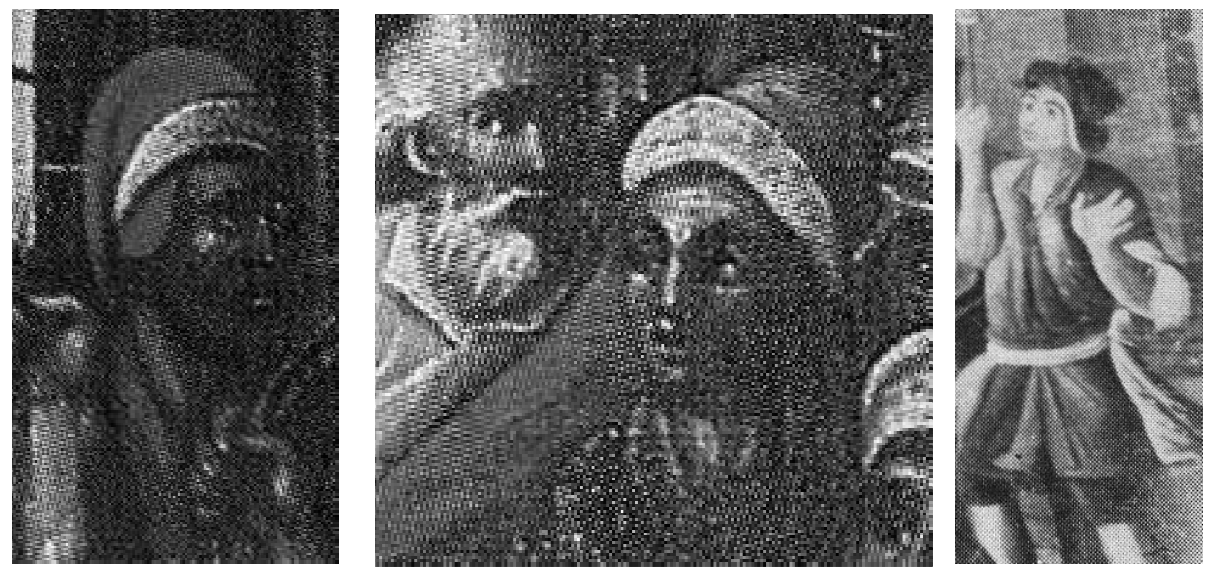

Detalhes das figuras 9 e 10.

Outros dois ciclos, também do século XVIII, sobre a vida do Cristo foram pintados para o claustro de Santa Teresa em Ayacucho. Um deles, composto de doze telas, agrega cenas relacionadas à Paixão; o outro, com dez pinturas, trata de diversos episódios narrados nos Evangelhos. Este é o caso de Herodes a Pilatos do Mestre de Santa Teresa (figura 12), que juntou elementos iconográficos de três pranchas diferentes de Imagens da História Evangélica com o objetivo de elaborar uma única pintura. No centro da tela vemos a captura do Cristo, à esquerda aquele que o interrogará e à direita, Pilatos.

\section{Figura 12}

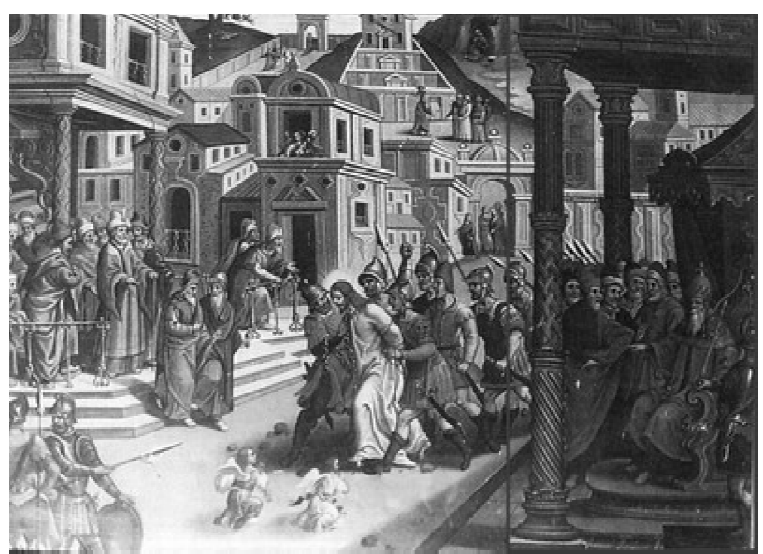

Mestre de Santa Teresa. De Herodes a Pilatos. Óleo sobre tela, século XVIII. Convento de Santa Teresa, Ayacucho. 
TATSCH, Flavia Galli. A circulação de gravuras flamengas no Vice-Reino do Peru: transferência de modelos e inventividade. Domínios da Imagem, Londrina, v. 9, n. 17, p. 7-25, jan./jun. 2015.

ISSN 2237-9126
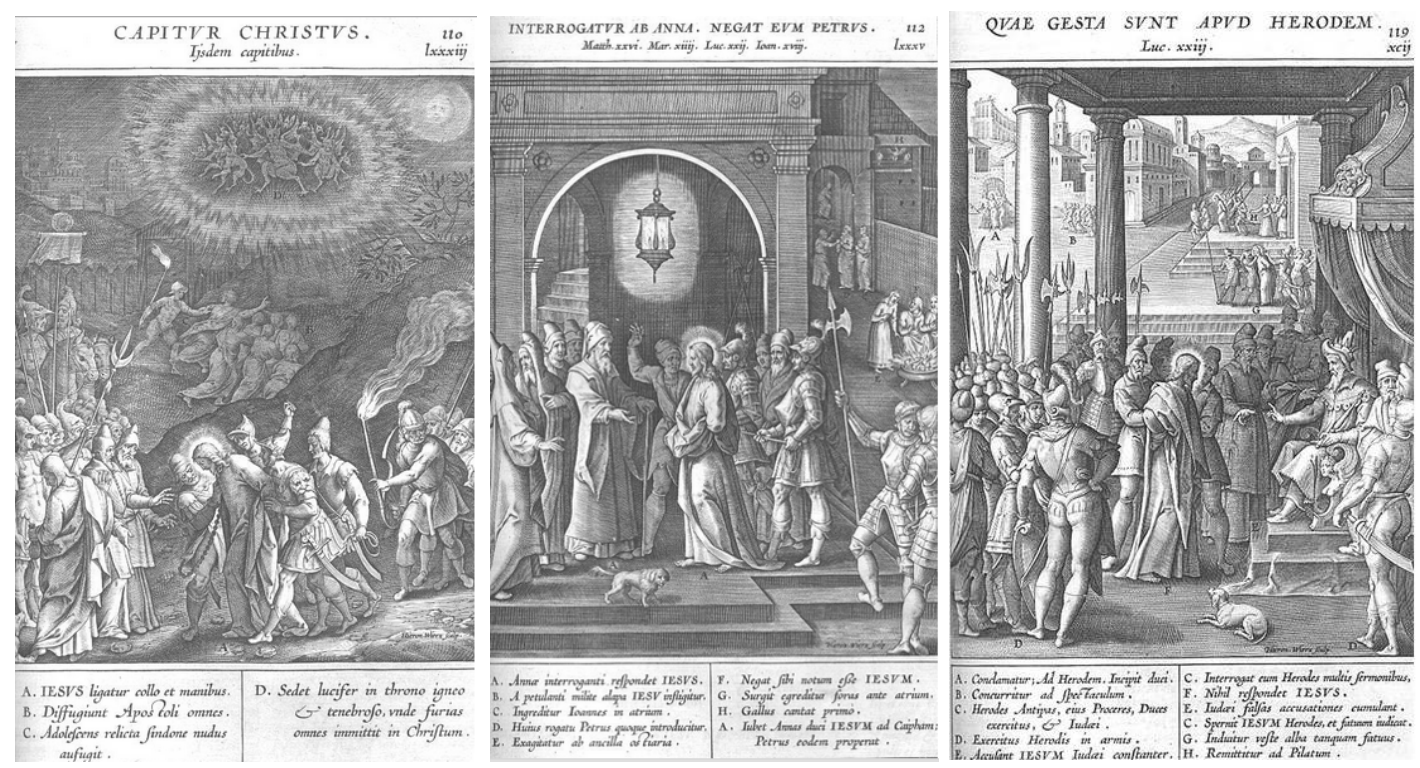

Figura 13 (esq.). WIERIX, Hieronimus. Lâmina 110. NADAL, Jerônimo. Evangelicae Historiae Imagines, 1593. Gravura.

Figura 14 (centro). WIERIX, Hieronimus. Lâmina 112. NADAL, Jerônimo. Evangelicae Historiae Imagines, 1593. Gravura.

Figura 15 (dir.). WIERIX, Hieronimus. Lâmina 119. NADAL, Jerônimo. Evangelicae Historiae Imagines, 1593. Gravura.

As gravuras utilizadas pelo Mestre para formar a composição final foram as de número 110 Captura de Cristo [Capitur Christvs] (figura 13), 112 Interrogado por Annas. Negação de Pedro [Interrogatvr ab Anna. Negat evm Petrus] (figura 14) e 119 O que aconteceu perante Herodes [Qvae gesta apvd Herodem] (figura 15). Ora, a inventividade do Mestre de Santa Teresa não se limitou apenas na escolha dessas gravuras. Importa perceber que ele pintou uma paisagem que nada tinha a ver com as das estampas, procurando juntar uma tradição flamenga de representação de cidades com elementos locais para que o público se sentisse identificado com o cenário representado, como é o detalhe da construção, ao fundo, que mais se parece com uma pirâmide pré-colombiana. 
TATSCH, Flavia Galli. A circulação de gravuras flamengas no Vice-Reino do Peru: transferência de modelos e inventividade. Domínios da Imagem, Londrina, v. 9, n. 17, p. 7-25, jan./jun. 2015.

ISSN 2237-9126

Nesse sentido, vale apresentar um último exemplo de apropriação das ilustrações do livro de Jerônimo Nadal, ainda que com diversas variantes: a de número 97 De Antichristo [O Anticristo] (figura 16) que serviu como base para a tela de mesmo nome elaborada, em 1739, para compor a série das Postrimerías da Igreja de Caquiaviri, em La Paz (figura 17). Segundo o catecismo da igreja católica, as Postrimerías são a morte, o juízo, o inferno e a glória: tudo o que se espera depois da morte.
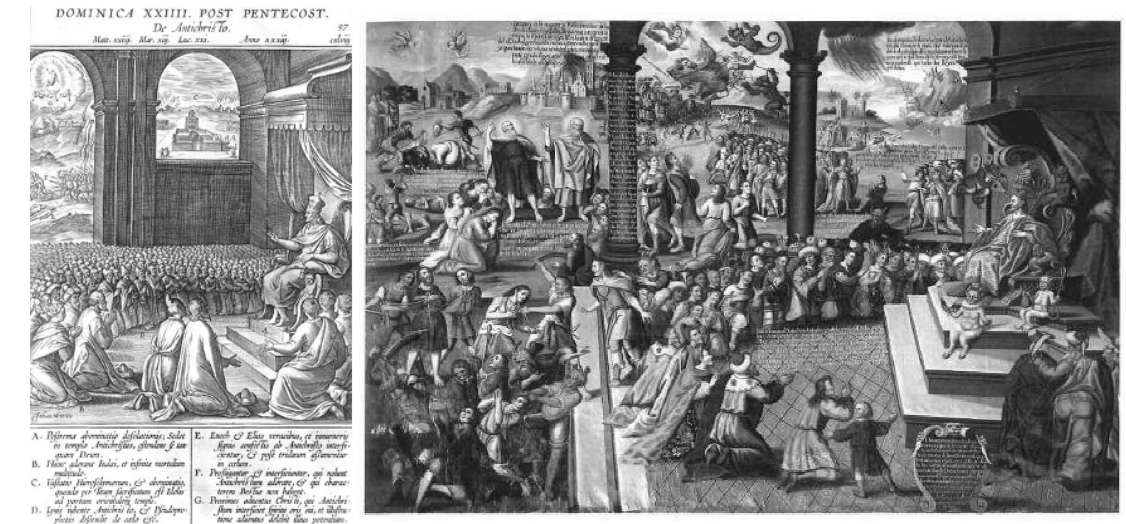

Figura 16 (esq.). WIERIX, Hieronimus. Lâmina 97 NADAL, Jerônimo. Evangelicae Historiae Imagines, 1593. Gravura.

Figura 17 (dir.). ANÔNIMO. Anticristo. Óleo sobre tela, 1739. Igreja de Caquiaviri, La Paz.

O Anticristo na série de Caquiaviri tinha como intenção explicar e advertir sobre o significado e as consequências da adoração de falsos deuses. Ou seja, era uma mensagem mais do que explícita, enviada aos indígenas sobre a idolatria. Na tela, entre os adoradores do Anticristo estão representados, lado a lado com judeus e islâmicos, representantes dos ameríndios. As cenas ao fundo também estão carregadas de significados. Da direita para esquerda, sob os arcos, percebe-se uma montanha na qual trabalham seres malignos e um texto em que se lê: "os demônios descobriram no Anticristo todo o ouro e a prata que estava escondido desde os princípios do mundo". Ora, Caquiaviri era uma zona onde 
TATSCH, Flavia Galli. A circulação de gravuras flamengas no Vice-Reino do Peru: transferência de modelos e inventividade. Domínios da Imagem, Londrina, v. 9, n. 17, p. 7-25, jan./jun. 2015.

ISSN 2237-9126

moravam indígenas obrigados a trabalhar nas minas de Potosí, daí a analogia entre os nativos considerados idólatras e os demônios do Anticristo.

Neste artigo, procuramos apontar alguns poucos exemplos do impacto das gravuras e da circulação dos elementos entre elas e a pintura do Vice-Reino do Peru. Para finalizar, consideramos importante frisar que a apropriação das estampas flamengas se dava dependendo do comitente da obra, do espaço em que ela deveria ser exposta e à qual público se destinava. Ou seja, sempre devemos observar a forma e o conteúdo, assim como o contexto da produção. Além disso, não podemos jamais afirmar que os artistas que se encontravam nos vice-reinos simplesmente imitavam práticas culturais europeias. O que devemos ter em mente é que geravam respostas aos modelos nas quais expressavam sua própria maneira de entender o mundo. Havia muito mais do que uma cópia, mais do que o olho poderia ver.

\section{Referências}

ALCALÁ, Luisa Elena. Las imágenes de Jerónimo Nadal y un Retablo Novo Hispano. UNAM, Anales del Instituto de Investigaciones Estéticas. Ciudad Mexico, XVI/64, 1993, p. 47-55. Disponível em: http://www.analesiie.unam.mx/pdf/64_47-55.pdf. Acesso em: 30 abr. 2015.

BUSER, Thomas. Jerônimo Nadal and Early Jesuit Art in Rome. The Art Bulletin, v. $58, \quad$ n. $3, \quad$ p. 424-433, sep. 1976. Disponível em: http://www.jstor.org/stable/3049533. Acesso em: 15 maio 2012.

BAILEY, Gauvin Alexander. Art of Colonial Latin America. Londres: Phaidon, 2005.

DEAN, Carolyn S. Copied Carts: Spanish Prints and Colonial Peruvian Paintings. The Art Bulletin, v. 78, n. 1, p. 98-110, mar. 1996. Disponível em: http://www.jstor.org/stable/3046159. Acesso em: 17 jun. 2915.

GISBERT C. Teresa; MESA, Andrés de; BOLIVIA. Los Grabados, El "Juicio Final" y La Idolatría Indígena en el Mundo Andino". Disponível em: http://dspace.unav.es/dspace/bitstream/10171/18507/1/04_Gisbert_Mesa.pd f. Acesso em: 17 jun. 2012. 
TATSCH, Flavia Galli. A circulação de gravuras flamengas no Vice-Reino do Peru: transferência de modelos e inventividade. Domínios da Imagem, Londrina, v. 9, n. 17, p. 7-25, jan./jun. 2015.

ISSN 2237-9126

KELEMEN, Pál. Baroque and Rococo in Latin America. New York: Dover Publications, 1967.

MANRIQUE, Jorge Alberto. La estampa como fuente del arte en la Nueva España. Anales del Instituto de Investigaciones Estéticas (Ciudad de México), n. 50, p. 55-60, 1982.

MESA, José de; GISBERT, Teresa. Holguín y la Pintura Altoperuana del Virreinato. La Paz: Biblioteca Paceña, 1956

MOXEY, Keith. Peasants, Warriors and Wives. Popular Imagery in the Reformation. Chicago and London: The University of Chicago Press, 2004.

NADAL CAÑELLAS, Juan. Jerónimo Nadal, Vida e influjo. Bilbao: Ediciones Mensajeros-Sal Terrae, 2007.

SALAZAR-SOLER, Carmen. El libro de los Países Bajos Meridionales en el Perú. In: THOMAS, Werner; STOLS, Eddy (Eds.). Un mundo sobre papel. Libros y grabados flamencos en el imperio hispanoportugués (siglos XVI-XVIIII). Louvain: Editorial Acco, 2009. p. 219-233.

SORIA, Martin. Una nota sobre pintura colonial y estampas europeas. Anales del Instituto de Arte Americano e Investigaciones Estéticas, p. 43-49, 1952. 